\title{
Involving consumers in health research: what do consumers say?
}

\author{
Angela $L$ Todd a,b,d and Don Nutbeam ${ }^{a, c}$ \\ a Sydney Health Partners, Charles Perkins Centre, University of Sydney, NSW, Australia \\ b The Kolling Institute, Sydney Medical School, University of Sydney, NSW, Australia \\ c Sydney School of Public Health, University of Sydney, NSW, Australia \\ d Corresponding author: angela.todd@sydney.edu.au
}

\section{Article history}

Publication date: June 2018

Citation: Todd AL, Nutbeam D. Involving consumers in health research: what do consumers say? Public Health Res Pract. 2018;28(2):e2821813. https://doi. org/10.17061/phrp2821813

\section{Key points}

- A consumer-driven health and medical research agenda is an integral component of a high-quality, patientcentred healthcare system

- Stronger involvement of consumers in health research requires improved understanding of research processes, greater transparency and clearer communications, and making involvement in research easier and a more positive experience

- Investment in education and communication strategies will help shift current models of how we do research and the roles that patients and consumers can play

\section{Abstract}

Objectives: To ensure that the contribution of patients and consumers in health research is better understood, respected and fully utilised.

Type of program or service: Consumer representative networks that form part of a broader quality improvement program in local health services.

Methods: Consultations were held with members of health consumer networks in Sydney, Northern Sydney and Western Sydney Local Health Districts, and the Sydney Children's Hospitals Network (at Westmead) about how to better involve consumers in health research.

Results: Feedback from 20 volunteers suggested that consumer involvement in research would be improved if: consumers understood more about research; communications clearly explained the research, why it was relevant to consumers and what might be involved; consumers' contributions were heard and respected; and being involved in research was made an easy and positive experience.

Lessons learnt: People want to be involved in health research, and have valuable contributions to make. We must ensure that the potential contribution of patients and consumers is fully utilised, and get a great deal better at communicating benefits and risks. 


\section{Introduction}

In Australia, Sydney Health Partners (SHP) is one of seven Advanced Health Research and Translation Centres (AHRTCs) accredited by the National Health and Medical Research Council (NHMRC). The AHRTCs are similar in concept to Academic Health Science Centres in the UK, the US, Canada and Europe. ${ }^{1}$ These centres comprise partnerships between two or more healthcare providers and universities, and bring together research, clinical service delivery, education and training. SHP includes three Local Health Districts (LHDs), the Sydney Children's Hospitals Network, the University of Sydney and nine affiliated medical research institutes. ${ }^{2}$ The partnership reaches a population of 2.7 million people, representing more than $10 \%$ of the Australian population. SHP describes its core purpose as "using the outcomes of health and medical research to improve the lives of our patients and community faster and more consistently". It aims to improve health services and health outcomes by better using existing research to drive high-quality care, and by conducting new research that directly addresses important challenges faced by our community and our healthcare providers. ${ }^{2}$

There have been widespread calls for broader involvement of healthcare consumers and the general public in health research, not only as research participants but also in defining research questions that matter most to them. 3,4 Greater consumer involvement in research has many potential benefits, including improved relevance of research to patient needs; greater accountability; improved quality and outcomes; decreased costs; more effective research translation; and improved public confidence in research. At the same time, barriers can exist for researchers (e.g. extra time and cost) and consumers (e.g. a lack of training, supervision and support in understanding the research process). There remain concerns that consumer involvement, where it occurs at all, is too often tokenistic and fails to engage consumers in ways that might directly impact on the research. ${ }^{5}$ Internationally, various approaches have been used to strengthen consumer involvement in health research (e.g. the James Lind Alliance in the UK (www.jla.nihr.ac.uk), the Patient-Centered Outcomes Research Institute in the US (www.pcori.org), and the Canadian Institutes of Health Research. ${ }^{4}$ In Australia, the primary national guide for responsible research practices advocates for appropriate consumer involvement in research ${ }^{6}$, and a related $\mathrm{NHMRC}$ document provides additional direction. ${ }^{7}$ In addition to these statements, several practical initiatives have been implemented to involve consumers in health research. ${ }^{8-11}$ Nonetheless, the Australian Medical Research and Innovation Strategy, 2016-2021 is critical of continuing limited consumer engagement in health research. ${ }^{12}$

In response to these ongoing concerns, SHP initiated a series of consultations to better understand how healthcare consumers might wish to influence and engage in the development and practical delivery of research.

\section{Consulting with consumers}

SHP's four health service partners have existing consumer engagement networks that form part of a broader quality improvement program in local health services. SHP worked in collaboration with the managers of these networks as part of a systematic process to get advice and feedback from consumers about issues related to participation in health research that would assist in continuing quality improvement activities in the health services. As such, the information reported was not gathered primarily for research purposes and was not the subject of normal research processes including ethics approval.

The network managers of the three LHDs sent an invitation by email to all members inviting expressions of interest to attend a 2-hour focus group to discuss how consumers can be more involved in designing research that matters most to them. The focus groups were to be held at one of the local hospitals in each LHD. For the remaining health service (the Sydney Children's Hospitals Network) an email to members offered one-on-one telephone interviews, since members were predominantly young adult patients and parents who might have more difficulty attending a focus group. The discussions were framed around two questions:

- How can researchers better engage patients and other healthcare consumers in the development of research questions that address priority issues from a patient/consumer perspective?

- How can researchers best communicate with patients and other healthcare consumers the importance of participating in research?

Participants were informed that focus-group discussions would be audio recorded and that notes would be taken during the individual telephone interviews. Our volunteers agreed to provide responses and feedback to our questions that would be summarised in report form for the benefit of all the partner organisations. Permission was not sought from participants to quote individual responses in other publications. The information from the discussions was subsequently analysed by one of the authors (AT) to identify the main themes for each question. The themes from each focus group and interview were then reviewed by both authors (AT, DN) to identify overlapping and distinct themes.

\section{Feedback from consumer}

\section{representatives}

Between December 2016 and April 2017, three focus groups ( $n=16$ participants) and four interviews were conducted with members of the participating consumer networks. Although specific demographic information was not collected, the volunteers included people of: different ages (from young adults through to the elderly); 
diverse socio-economic and cultural backgrounds (including participants from culturally and linguistically diverse communities); and various healthcare conditions and experiences (including mental illness, physical disabilities, complex and chronic conditions, and rare diseases). Most of the people who were consulted had had direct experience as research participants/subjects and viewed health research as a social good that could contribute to better healthcare.

\section{How can researchers better engage with health consumers about their research priorities?}

\section{Help us understand more about research}

Several volunteers informed us that many in the general public have little awareness of, or experience with, health research and how or why it might be relevant to them. Marketing and education strategies were needed to explain the role of research in healthcare, how people can recognise 'good quality' research, and what kind of information they should have to be well informed. Some expressed concerns about being "used" or "having things done to you without your knowledge or consent" and that these concerns should be acknowledged and addressed. People with complex or rare health conditions spoke of feeling especially vulnerable to being "used" or "experimented with", both by clinicians and researchers. Some wanted to better understand the balance between doing new research versus using existing research evidence, and the balance between investing in research to manage or treat illnesses versus research to help keep people healthy.

\section{Listen to us and respect what we say}

We received consistent and clear advice that researchers need to be willing to really listen. The volunteers wanted to be confident that they would be respected and their voices heard, and that researchers would be open to having their ideas and plans challenged or even changed. They also wanted to be acknowledged as experts in their own health conditions and care needs; they were the ones with the lived experiences. This point was also made by the young adults we interviewed, who, as children with chronic conditions, often felt ignored and spoken about but not to. Some volunteers recommended that researchers receive training in how to better listen to and speak with consumers.

\section{Be totally honest with us}

We received strong feedback about the importance of transparency in research, including clear communications about: the purpose of the research; risks and benefits; how consumer input could be used; how results would be shared with study participants; what impact the results would have on healthcare and peoples' health outcomes; and what resources would be available at the end of the study to use the results. They also told us that methods of communication needed to be culturally and socially relevant to the target audience (including translated materials where appropriate).

\section{Make it easy for us to get involved}

We received practical suggestions to facilitate consumer involvement in research. These included: establishing a register of interested consumers who would be willing to be approached about upcoming research projects; providing enough information (not too little, not too much) in a style that was easy to understand for nonresearchers; and attending or hosting community-based forums where people could make suggestions about health research questions.

\section{How can researchers best communicate with health consumers about participating in research?}

\section{You've got to sell it!}

We received clear advice that people needed to be better convinced why research is relevant and important to them, and why they should participate. Providing examples of where research has made a significant contribution to improving health would help demonstrate that research was worthwhile. To increase participation, multiple communication and marketing strategies were suggested, including general messages about health research as well as targeted messages to potential participants for specific research projects. Our volunteers reiterated the need for plain English and culturally appropriate concepts, and suggested using multiple formats, such as posters, pamphlets, letters, internet, apps, registries and news media (TV, radio, newspapers).

\section{Go where people are}

Our volunteers recognised that health settings offer numerous locations where patients and members of the public may be sitting and waiting for extended periods and can be approached about research participation. But they also suggested leveraging community networks and common settings where people gather, such as sporting and social clubs, cultural and other community centres, schools (parents, grandparents), public libraries, churches and volunteer groups (e.g. Lions and Rotary Clubs).

\section{Tell the whole story}

We received clear and consistent advice about the importance of transparency in research, especially the risks and benefits, time commitments, and planned use of results. Several volunteers also emphasised the importance of study participants receiving feedback about a project, even if it was some years later, so that they can see the value of their contribution. Tellingly, none of our participants who had been involved in research had ever received feedback about the results. 


\section{Make it a positive experience}

Several of our volunteers reported disappointing experiences with practical aspects of engaging in research, citing poor communication, inefficient administrative processes and slow reimbursement of expenses as potential barriers to their future participation as well as their likely recommendation to others.

\section{One size doesn't fit all}

It became clear from the feedback we received that some patient and population groups require different or additional efforts to engage in research. For example, some volunteers mentioned age as a factor, with young, healthy adults being less interested in research about health conditions that are not relevant to them at this stage in their lives. Others suggested that some cultural groups may avoid participating in health research because of language difficulties, a lack of familiarity with research concepts or cultural preferences. Several volunteers who were carers of sick children or elderly people with complex health conditions (including dementia) identified specific sensitivities concerning research that was "done to them". For example, among our volunteers, those who had been children with chronic and/or rare health conditions commented about how doctors and parents had made decisions about their involvement in research or experimental procedures, but that they had also wanted to be consulted about what happened to them.

\section{Discussion and conclusion}

Our early consultations with patient and carer representatives suggest that people do want to be involved in health research, and have valuable contributions to make. The findings indicate that we need to make it easier for them to do so, ensure that their potential contribution is respected and fully utilised, and get a great deal better at communicating benefits and risks. The volunteers in this project provided a number of concrete suggestions about how to more effectively involve patients and consumers in research. There was a perceived need to better promote the importance of health research and how it contributes to better healthcare and better health outcomes. A recent survey found that $66-70 \%$ of Australians recognise the importance of health and medical research for improving our health system, developing new drugs and medical devices, and delivering better health outcomes. Importantly, $84 \%$ believe that health professionals who see patients and also undertake research provide the best care because they are more aware of new developments and the latest practices. ${ }^{13}$ These specific benefits of research should be included in promotional campaigns.

Our volunteers emphasised the importance of knowing the specific details of individual projects so that people can make well-informed decisions about whether to be involved and what they can expect, including risks and benefits. Information needs to be tailored to the audience using nonscientific language and culturally appropriate concepts, and needs to clearly articulate the relevance (or not) of the research to the individual. This indicates a need to use targeted and different approaches, rather than expecting one solution to work for everyone every time.

The feedback from our discussions also challenges researchers to change - specifically, to be more respectful and honest with patients and carers about research, to listen and acknowledge what they say, and to accept and value the knowledge patients and carers bring from their lived experiences with illness. Researchers were also asked to improve the research experience. Our participants spoke of discourteous and inconsiderate behaviour (especially with respect to people's time and convenience), and suggested simple logistical improvements such as reimbursing parking costs.

Our observations are consistent with other reports about how to better involve consumers in health research,, 59 and also align with a proposed framework for consumer engagement in health research. ${ }^{14}$ Models and tools exist to help researchers and their organisations to promote consumer engagement in health research. The Consumer and Community Health Research Network in Western Australia has developed an extensive suite of resources including guidance for establishing reference and steering groups, writing tips for communicating with consumers, and how to involve consumers in grant applications. It also offers several training programs for consumers and researchers. ${ }^{8}$

This project was an initial foray for Sydney Health Partners into better understanding the views of patients and carers about health research. Participants were drawn from consumer networks among our partner organisations. People who volunteer do not represent the voices of all in the community, and commonly underrepresent younger people, people of lower socioeconomic status, and people from a range of minority groups. ${ }^{15}$ Although the number of participants in our study was relatively small, we had representation from several of these harder-to-reach groups. But our sample did not include healthy people who have little or no contact with hospitals and tertiary care, and was also limited to people living in metropolitan Sydney. Although this potentially affects the generalisability of the results, our findings are consistent with results reported in other broader consumer consultations.

Sydney Health Partners is committed to supporting greater consumer and community involvement in health research and translation activities. Our next steps are to work with our partner organisations to develop promotional and educational resources about the value of health research and research participation, to facilitate access to training and other resources for healthcare 
providers and researchers about involving consumers in research, and to monitor consumer and community involvement activities across our partnership. ${ }^{16}$ Importantly, our partner hospitals and LHDs have already established active consumer networks. Although largely focused on improving patient care, they are increasingly interested in contributing to health research, as reflected in the current project.

\section{Acknowledgements}

The contributions of the 20 patient and carer representatives who participated in the consultations are gratefully acknowledged. The following health personnel provided invaluable assistance in recruiting the participants in the consultations: Anthony Marsh, Northern Sydney LHD; Coralie Wales and Tara Lee, Western Sydney LHD; Timothy Morcombe and Nicholas Bates, Sydney LHD; and Laura Griffin, Kelly Bowler and Bianca Pratt, Sydney Children's Hospitals Network (at Westmead). All have received a copy of the report of the consultation project including initial recommendations. ${ }^{16}$

\section{Peer review and provenance}

Externally peer reviewed, not commissioned. DN is the Editor-in-Chief of Public Health Research \& Practice. He had no part in the peer review process for this paper.

\section{Competing interests}

None declared.

\section{Author contributions}

DN conceived the original project. AT was responsible for design and conduct of the consultations. The manuscript and subsequent revisions were drafted by AT and reviewed by DN.

\section{References}

1. French CE, Ferlie E, Fulop NJ. The international spread of academic health science centres: a scoping review and the case of policy transfer to England. Health Policy. 2014;117(3):382-91

2. Sydney Health Partners. Sydney Health Partners: translating research into better health outcomes. Sydney: Sydney Health Partners; [cited 2018 May 17]. Available from: www.slhd.nsw.gov.au/sydneyhealthpartners/pdf/ Sydney\%20Health\%20Partners\%20on\%20a\%20Page.pdf

3. Mullins C, Abdulhalim AM, Lavallee DC. Continuous patient engagement in comparative effectiveness research. JAMA. 2012;307(15):1587-8.
4. Canadian Institutes of Health Research. Strategy for patient-oriented research: putting patients first. Patient engagement framework. Ottawa: CIHR; 2014 [cited 2018 Apr 26]. Available from: www.cihr-irsc.gc.ca/e/ documents/spor_framework-en.pdf

5. Domecq JP, Prutsky G, Elraiyah T, Wang Z, Nabhan M, Shippee N, et al. Patient engagement in research: a systematic review. BMC Health Serv Res. 2014;14(1):89.

6. National Health and Medical Research Council, the Australian Research Council, Universities Australia. Australian code for the responsible conduct of research. Canberra: Australian Government; 2007 [cited 2018 Apr 26]. Available from: www.nhmrc.gov.au/_files_nhmrc/ file/research/research-integrity/r39_australian_code_ responsible_conduct_research_150811.pdf

7. National Health and Medical Research Council. Statement on consumer and community involvement in health and medical research. Canberra: NHMRC; 2016 [cited 2018 Apr 26]. Available from: www.nhmrc.gov.au/_ files_nhmrc/file/publications/16298_nhmrc_-_statement_ on_consumer_and_community_involvement_in_health_ and_medical_research-accessible.pdf

8. Involving People in Research. Perth: Consumer and Community Health Research Network, Western Australian Health Translation Network; 2017 [cited 2018 Apr 27]; [about 5 screens]. Available from: www. involvingpeopleinresearch.org.au/

9. Health Consumers NSW, Research4Me. Involving health consumers in health and medical research: enablers and challenges from a consumer perspective. Sydney: Health Consumers NSW, Research4Me; 2017 [cited 2018 Apr 27]. Available from: www.hensw.org.au/data/ Involving_health_consumers_in_health_and_medical_ research_online_print.pdf

10. Tong A, Crowe S, Chando S, Cass A, Chadban SJ, Chapman JR, et al. Research priorities in CKD: report of a national workshop conducted in Australia. Am J Kidney Dis. 2015;66(2):212-22.

11. NHMRC Cognitive Decline Partnership Centre. Midterm report. Canberra: NHMRC; 2016 [cited 2018 Apr 26]. Available from: sydney.edu.au/medicine/cdpc/ documents/about/CDPC-MidTermReport.pdf

12. Medical Research Future Fund. Australian medical research and innovation strategy, 2016-2021. Canberra: Australian Government; 2016 [cited 2018 May 15]. Available from: research.unimelb.edu.au/_data/assets/ pdf_file/0003/2545635/Australian-Medical-Research-andInnovation-Strategy-2016-2021.pdf

13. Research Australia. Australia speaks! Research Australia opinion polling 2016. Sydney: Research Australia; 2017 [cited 2018 Apr 27]. Available from: researchaustralia. org/wp-content/uploads/2016/01/Research-Australia_ Polling-Report-2016.pdf 
14. Miller CL, Mott K, Cousins M, Miller S, Johnson A, Lawson T, Wesselingh S. Integrating consumer engagement in health and medical research - an Australian framework. Health Res Policy Syst. 2017;15(1):9.

15. Galea S, Tracy M. Participation rates in epidemiologic studies. Ann Epidemiol. 2007;17(9):643-53.
16. Sydney Health Partners. Engaging consumers in health research: report of initial consultations. Sydney: SHP; 2017 [cited 2018 Apr 27]. Available from: www.slhd.nsw.gov.au/sydneyhealthpartners/pdf/ EngagingConsumersHR.pdf

\section{Copyright: (c) (i) (2)}

(C) 2018 Todd and Nutbeam. This article is licensed under the Creative Commons Attribution-NonCommercial-ShareAlike 4.0 International Licence, which allows others to redistribute, adapt and share this work non-commercially provided they attribute the work and any adapted version of it is distributed under the same Creative Commons licence terms. See: www.creativecommons.org/licenses/by-nc-sa/4.0/ 